\title{
Chronic Exposure to Pesticides- Neurological, Neurobehavioral and Molecular Targets of Neurotoxicity
}

\author{
Binukumar B.K and Kiran Dip Gill \\ Department of Biochemistry, Postgraduate Institute of \\ Medical Education and Research, Chandigarh, \\ India
}

\section{Introduction}

There is an increasing concern regarding the widespread use of pesticides and their potential impacts on public health. Pesticides differ from other chemical substances because they are toxic chemicals deliberately spread into the environment with the aim of controlling undesired living species. Since their toxicity may not be completely specific for the target organisms, their use may pose a risk to human health. Pesticide poisoning remains a serious public health problem worldwide. More than 5 billion pounds of pesticides are used annually worldwide, with about $25 \%$ being used in the United States (US Environmental Protection Agency 2001, 2002). Pesticide exposure occurs during their application, via their drainage into water supplies, and through the consumption of food. According to the World Health Organization's estimate, 3 million cases of pesticide poisoning occur every year, resulting in more than 250,000 deaths. This number also accounts for a substantial fraction of the almost 900,000 people worldwide who die by suicide every year. Organo-phosphorus pesticides (OPs) are currently the most commonly utilized pesticides in the world, consisting of nearly 40 different chemical members registered by the US-EPA (www.epa.gov). About 73 million pounds of OP pesticides were used in the United States above in 2001 (70\% of all insecticides; Kiely et al.,2004).

Pesticide poisonings are relatively common in countries such as Sri Lanka, Venezuela, Indonesia, South Africa, and Brazil. Among numerous pesticides that can result in death, organophosphate insecticides are the most common culprit agents because of their high toxicity. In developing countries, in which the use of OP compounds is particularly widespread because the hot climatic conditions, the number of deaths may be high. There is an increasing concern regarding the widespread use of pesticides and their potential impacts on public health. In the United States, a mixture of pesticide residues are detected in blood and/or urine of nearly all persons sampled (Barr et al., 2005). During the 1990s some 2.5-5.0 million agricultural workers were exposed to OPs, which are used as insecticides around the world (Abou-Donia, 2003; Das et al., 2001; Farahat et al., 2010; London et al., 1997). Although OPs are increasingly restricted for use in the US (EPA, 2002), many of the pesticides that are no longer available in the US and other developed countries are still being produced and used in agricultural or urban applications in developing countries. 
The mechanism of action of pesticides frequently involves a neurotoxic effect: organophosphorous compounds act through the inhibition of central nervous system cholinesterase (Jeyaratnam and Maroni, 1994; Machemer and Pickel, 1994); pyrethroids affect the sodium channels of the nerve membrane, keeping them open for more than the few milliseconds needed for the generation of the action potential (He, 1994); organochlorinated compounds in general act as central nervous system stimulants, but the mechanism of action varies for the different active ingredients (Tordoir and Van Sittert, 1994); morpholine derivatives alter the balance between excitatory and inhibitory threshold in neurons, impairing the function of the nervous system (Barbieri and Ferioli, 1994), while formamidines have an agonistic action on the alpha-2 catecholamine receptor (Xue and Loosly,1994).

Organophosphate $(\mathrm{OP})$ pesticides can produce several distinct neurotoxic effects depending on the dose, frequency of exposure, type of OP, and host of other factors that influence susceptibility and sensitivity. These effects include acute cholinergic toxicity, a delayed ataxia known as organophosphorus ester-induced delayed neurotoxicity (OPIDN), chronic neurotoxicity and developmental neurotoxicity. Acute cholinergic syndrome, due to the inhibition of ace-tylcholinesterase activity, which occurs within minutes or hours following exposure, usually subsides within days or weeks, and plasma or erythocytic acetylcholinesterase activity are used for monitoring acute exposure to OP (Lessenger and Reese, 1999); Acute OP pesticide exposure can involve wide range of both central and peripheral neurologic symptoms. Increased neurologic symptom prevalence may provide early evidence of neurologic dysfunctions, before clinically measurable signs are evident. Rastogi et al (2010) analyzed the cross-sectional data on neurologic signs and symptoms from 225 rural children, both males $(n=132)$ and females $(n=93)$ who were occupationally and paraoccupationally exposed to methyl OPs (dichlorvos, fenthion, malathion, methyl parathion) and ethyl OPs (chlorpyrifos, diazinon, ethyl parathion) as they belonged to agricultural families handling, mixing, and spraying the OP pesticides. Among all the neurologic self-reported symptoms, headache, watering in eyes, and burning sensation in eye/face were the most important clinical manifestations attributed to OP pesticide exposure. These symptoms could probably be the consequence of chronic effects of most pesticides on the central nervous system. The high frequency of neurologic symptoms observed in the study may be due to parasympathetic hyperactivity due to the accumulated ACh resulting from AChE inhibition (Rastogi, 2010).

Intermediate syndrome, which usually starts 24 to 96 hours after the acute syndrome and is characterized by respiratory paresis, weakness, depressed tendon reflexes, and transient extrapyramidal symptoms, without response to treatment with the cholinergic receptor antagonist atropine (Bhatt et al., 1999; Mileson et al., 1998; Senanayake and Johnson, 1982; Shahar and Andraws, 2001); Organophosphate-induced delayed neuropathy, which is a symmetric distal neuropathy, usually occurring weeks following an acute exposure probably related to the inhibition of the enzyme neuropathy-target esterase present in the nervous system (Aiuto et al., 1993).

Long-term exposure to relatively low levels of OP agents occurs in a variety of environments. Pesticides are often applied in a combination with several classes of compounds featuring synergistic interactions. One of the neurological functions for which an adverse effect of neurotoxic pesticides has been repeatedly hypothesized is behaviour. Behaviour is the product of various sensory, motor and associated functions of the nervous system, and the hypothesis is that neurotoxic substances can adversely affect one or more of these functions, disrupt learning and memory processes, or cause detrimental behavioural 
effects (IPCS/WHO, 2001). Since behaviour is a very complex system, made of several different functions and biochemical activities, it can be studied only based on a very complex approach, in which different tests are performed, addressed at a large spectrum of functions, in some cases with different approaches for different population subgroups (Anger et al., 2000; Cassitto et al., 1990; Fiedler et al., 1996; Krasnegor et al., 1995; Wetherell, 1996), and conclusion can be drawn only from an integrated evaluation of the available data. Because of this complexity, not surprisingly, different approaches have been chosen by different researchers, making comparisons between different studies very difficult. However, neurobehavioral toxicity is a very important issue for prevention, because some of the compounds thought to be involved are largely used in agriculture, and large sections of the human population are occupationally and/or environmentally exposed, including possible vulnerable subgroups such as children or pregnant women. (Colosio et al, 2009). An increasing number of papers have been and are being published on neurobehavioral effects of pesticides. However, besides what is well established (e.g. acute effects; OP induced delayed polyneuropathy; intermediate syndrome) (Jayawardane et al., 2009; Lotti, 2001; Lotti and Moretto, 2005), several uncertainties still remain on the real risks for workers and consumers of developing neurobehavioral changes after long-term exposures to low doses of neurotoxic pesticides (Colosio et al., 2003; Moser, 2007). Experimental data on neurotoxicological outcomes in animals are abundant, but relatively few are those studies dealing with long-term exposures (for a review see Moser, 2007). In fact, most reports in the literature deal with repeated exposures to pesticides, mainly OPs, as short as five days and rarely longer than three months. In addition, an even lower number of studies assessed neurobehavioral performance days or weeks after end of exposure.

In southern Brazil, agricultural workers involved in tobacco plantation use a combination of OP (chlorpyrifos and acephate), herbicides (glyphosate and clomazone), plant growth regulators (flumetralin), fungicides (iprodione), and insecticides (imidacloprid). Exposure to $\mathrm{OP}$ is known to induce clinical syndromes and biochemical alterations in humans. Besides acute cholinergic symptoms, which are related to the inhibition of acetylcholinesterase activity, acute or chronic OP exposure can also induce delayed toxic and behavioral effects not clearly related to the inhibition of esterases (Brown and Brix, 1998; Jamal, 1997; Mileson et al., 1998; Peter and Cherian, 2000; Sudakin et al., 2000). Most of the actions of OP on the nervous system seem to be related to organophosphorylation of protein targets, as acetylcholinesterase and neuropathy target esterase, or directly to binding of OP to nicotinic receptors (Mileson et al., 1998).

Chronic organophosphate-induced neuropsychiatric disorders (COPIND) are a less wellcharacterized syndrome in chronic OP poisoning. COPIND may be caused by chronic lowlevel exposure to OP, without cholinergic symptoms (Ray and Richards, 2001). The underlying mechanisms are not established, but are not dependent on inhibition of esterases (Levin et al., 1976) The most common clinical symptoms include impairment in memory, concentration, and learning; anxiety, depression, psychotic symptoms, chronic fatigue, peripheral neuropathy, autonomic dysfunction and extrapyramidal symptoms such as dystonia, resting tremor, bradikynesia, postural instability and rigidity of face muscles; and nonresponsiveness to levodopa treatment. Regarding psychiatric symptoms, neurobehavioral effects of low-level pesticide exposure have not been extensively studied with standardized, quantitative neuropsychologic batteries.

OPs do not accumulate in living organisms and the acute signs and symptoms disappear as the AChE activity returns to normal level. Therefore, they are regarded as relatively safe. 
However, as some literature data suggest, after either acute or prolonged exposure to OPs subtle neurobehavioral impairments may persist long after normalization of AChE activity. The possibility that OPs exposure may induce such long-term effects is nowadays a problem of great concern for the regulatory agencies. Rodnitzky et al, (1975) and Durham et al, (1965) in their cross-sectional epidemiologic studies using neurobehavioral tests have suggested that subtle behavioural impairments among pest control workers, farmers, and manufacturing workers are related to low level pesticide exposure or are persistent effects of severe acute pesticide poisoning (Metcalf and Holmes, 1969; Burkhart et al, 1978; Korsak and Sato, 1977; Levin et al, 1976; Xintaras et al, 1978; Savage et al, 1983, reviewed by; Johnson and Anger, 1983). There are also numerous case reports and case registries indicating that $4-9 \%$ of individuals with acute organophosphate poisoning experience delayed or persistent neuropsychiatric effects, including depression, weakness, nervousness, irritability, fatigue, insomnia, forget fulness, confusion, and schizoid and depressive reactions (Gershon and Shaw, 1961). Behavioural impairments due to pesticide exposure have also been implicated in serious accidents among agricultural workers (Redhead, 1968; Wood et al, 1971; Smith et al, 1968).

Amr et al. (1997) found that, compared to controls, subjects heavily exposed to pesticides (40 $\mathrm{h}$ /week, 9 months/year) had a significant increase in the frequency of psychiatric disorders, especially depressive neurosis and dysthymic disorder (DSM-III-R). These results left unresolved issue of reversibility of psychiatric symptoms after a pesticide-free period and the occurrence of syndrome in subjects not so heavily exposed to OP compounds. Another confounding factor in these studies has been the exposures to several types of pesticides which has been shown to reproduce features of Parkinson's disease (Binukumar et al, 2010). Some of the factors which have been shown to influence the feasibility of an epidemiologic appraisal of CNS abnormalities among pesticide workers depend upon: 1) the extent to which exposure can be quantified; 2) the multiplicity of chemical exposures; 3) the sensitivity and specificity of the neurobehavioral test; and 4) the time taken to conduct the test. Stephens, et al (1995) studied the relationship between chronic (nonreversing) neuropsychological effects and acute exposure effects and investigated 77 organophosphate-exposed male sheep-dippers. Acute exposure effects were assessed prospectively using a purpose-constructed symptoms questionnaire administered pre-, and $24 \mathrm{~h}$ post exposure. Urine was analysed for dialkylphosphate levels to confirm recent exposure. Chronic effects were assessed in a cross-sectional neuropsychological study in the absence of recent exposure using computerized neuropsychological tests, the General Health Questionnaire, and the subjective Memory Questionnaire. Simple correlation and multiple linear regression analyses, were used to assess relationships between the changes in total symptoms reporting from baseline to $24 \mathrm{~h}$ after exposure and chronic effect outcomes. There was no evidence of any association between reported symptom levels and chronic neuropsychological effects. This suggests that chronic effects of OP exposure appear to occur independently of symptoms that might immediately follow acute OP exposure. This has implications for exposure control: individuals may experience chronic effects without the benefit of earlier warning signs of toxic effects during acute exposures.

Military personnel returning from the Gulf War (GW) have reported symptoms that have not only diagnosis using known disease entities but also do not appear to occur in a predictable constellation that can be classified as a single syndrome (Persian Gulf Veterans Coordinating Board, 1995; Institute of Medicine, 1996; Iowa Persian Gulf Study Group, 1997; Proctor et al., 1998; Wolfe et al., 1998). However, prominent among complaints reported by a 
high percentage of several samples of GW veterans are symptoms that suggest dysfunction in the central nervous system (CNS). These include memory loss, concentration problems, headaches, and fatigue. Freya Kame et al (2005) analyzed cross-sectional data from 18,782 white male licensed private pesticide applicators enrolled in the Agricultural Health Study in 1993-1997. Applicators provided information on lifetime pesticide use and 23 neurologic symptoms typically associated with pesticide intoxication. Among chemical classes of insecticides, associations were strongest for organophosphates and organochlorines. Associations with cumulative exposure persisted after excluding individuals who had a history of pesticide poisoning or had experienced an event involving high personal pesticide exposure. These results suggest that self-reported neurologic symptoms are associated with cumulative exposure to moderate levels of fumigants and organophosphate and organochlorine insecticides, regardless of recent exposure or history of poisoning.

\section{Behavioural studies in animals}

Chronic exposure of rats to one tenth of the LC50 of sarin for 30 days induced a decrease in M1 receptors in the olfactory tubercle, changes in blood and brain ChE activities and the expression of cytokines mRNA levels (Henderson et al., 2002). Guinea pigs receiving 0.3, 0.4 or $0.5 \times$ LD50 of repeated sarin injections exhibited disrupted sleep pattern in the EEG (Shih et al., 2006) and a decrease in red blood cell AChE to a low level of baseline. Obvious signs of cholinergic toxicity were observed only in animals receiving sarin. Experiments involving the application of multiple low-doses of soman induced alterations in long-term potentiation (Armstrong et al., 1997). We also reported dichlorvos administration caused a marked decrease in both the ambulatory and stereotypic components of spontaneous locomotor activity of rats. The muscle strength and coordination of the dichlorvos-treated animals was also significantly impaired. Besides, a marked deterioration in the memory function assessed in terms of the conditioned avoidance response was discernible at the end of the treatment schedule in the experimental animals (Sarin and Gill KD, 1998). In a series of experiments Gralewicz and Soćko (1997) have demonstrated that exposures to 2-chloro-1(2,4-dichlorophenyl) vinyl diethyl phosphate (CVP) in rabbit resulted in a similar inhibition of blood AChE activity but the effect of the second exposure on body temperature and hippocampal EEG was smaller and less consistent than that of the first one. This would indicate that some permanent changes within the CNS may occur even after a single exposure to CVP. They also studied the CVP exposure in rat. One injection/day for ten days at a symptomatic $(3.0 \mathrm{mg} / \mathrm{kg})$ dose inhibiting blood and brain AChE activity by about $80 \%$, the tolerance to $\mathrm{CVP}$, assessed from the spontaneous locomotor behaviour, developed within four to five days. However, single exposure to CVP at a symptomatic $(3.0 \mathrm{mg} / \mathrm{kg})$ or subsymptomatic $(1.0 \mathrm{mg} / \mathrm{kg}$, less than $50 \%$ AChE inhibition) dose, or repeated exposure (one injection/day, for ten days) at subsymptomatic doses $(1.0 \mathrm{mg} / \mathrm{kg}$ or $0.5 \mathrm{mg} / \mathrm{kg}$ ) resulted in subtle changes in complex behaviours detectable after AChE activity in blood and in the brain had returned to the normal level. The changes neophobia in the open field, an increased and more persistent emotional response to a stressful stimulus, and increased EEG arousal response to an external pain signalling stimulus suggest an increased reactivity of the system or systems responsible for the induction of fear. Direct intrahypothalamic injections of CVP, unlike those of oxotremorine, a direct stimulant of cholinergic muscarinic receptors, did not induce overt changes in the animal (rabbit) behaviour and EEG. This would indicate that the changes in the CNS functions after CVP exposure may be the 
consequence of increased cholinergic activity due to AChE inhibition rather than to a direct stimulation of cholinergic muscarinic receptors by CVP. The above findings provide experimental evidence that health effects of exposure to CVP, may persist after recovery of AChE activity in blood and in the brain. (Gralewicz and Soćko ,1997).

Alvin et al (2007) have demonstrated that rats when injected with CPF subcutaneously (dose range, $2.5-18.0 \mathrm{mg} / \mathrm{kg}$ ) every other day over the course of 30 days, and then given a two week, CPF-free washout period, dose dependent decrements in a water maze hidden platform task and a prepulse inhibition procedure were observed during the washout period, without significant effects on open field activity, rotarod performance, grip strength, or a spontaneous novel object recognition task. After washout, levels of CPF and its metabolite 3,5,6-trichloro-2-pyridinol (TCP) were minimal in plasma and brain, however, cholinesterase inhibition was still detectible. Further, the $18.0 \mathrm{mg} / \mathrm{kg}$ dose of CPF was associated with (brain region-dependent) decreases in nerve growth factor receptors and cholinergic proteins including the vesicular acetylcholine transporter, the high affinity choline transporter, and the nicotinic acetylcholine receptor. These deficits were accompanied by decrease in anterograde and retrograde axonal transport measured in sciatic nerves exvivo. Thus, low-level (intermittent) exposure to CPF has persistent effects on neurotrophin receptors and cholinergic proteins, possibly through inhibition of fast axonal transport. Such neurochemical changes may lead to deficits in information processing and cognitive function. We report that (Binkumar et al, 2010), chronic OP (dichlorvos) exposure ( $2.50 \mathrm{mg} / \mathrm{kg}$ b.wt.s.c/daily for 12 weeks) can also caused nigrostriatal dopaminergic degeneration. The degenerative changes were accompanied by a loss of $60-$ $80 \%$ of the nigral dopamine neurons and $60-70 \%$ reduction in striatal dopamine and tyrosine hydroxylase levels. Dichlorvos exposed animals also showed a-synuclein and ubiquitin positive inclusions along with swollen, dystrophic neurites and mitochondrial abnormalities like decreased complex I\&IV activities, increased mitochondrial size, axonal degeneration and presence of electron dense perinuclear cytoplasmic inclusions in the substantia nigra of rats. These animals also showed evidence of oxidative stress, including increased mitochondrial ROS levels, decreased MnSOD activity and increased lipid peroxidation. Measurable impairments in neurobehavioral indices were also observed. Notable exacerbations in motor impairments, open field and catalepsy were also evident in dichlorvos exposed animals. All these findings taken together indicate that chronic dichlorvos (OP) exposure may cause nigrostaital neurodegenaration and significant behavioral impairments. Phenytoin (PHT) exposure in utero of rats demonstrate abnormal circling, decreased learning, hyperactivity, and delayed air righting reflex development. The effects of prenatal PHT on offspring learning have been found on multiple-T mazes and on spatial navigation (Morris maze). PHT-exposed offspring showed increased preweaning mortality, growth reduction, and abnormal circling. PHT noncircling offspring demonstrated impaired reference memory-based spatial learning (acquisition and reversal), but no other effects. By contrast, PHT circling offspring demonstrated not only impaired reference memory-based spatial learning, but also impaired cued platform learning, impaired spatial discrimination, and impaired working memory-based learning. These data confirm that prenatal PHT induces a specific reference memory-based spatial learning deficit even in asymptomatic (noncircling) offspring that is distinct from the impairment induced in littermates exhibiting the circling impairment. Recently we reported that chronic $\mathrm{OP}$ exposure (dichlorvos) may lead to significant increase in mitochondrial $\mathrm{Ca} 2+$ uptake. 
Our results also indicated decreased mitochondrial electron transfer activities of cytochrome oxidase (complex IV) along with altered mitochondrial complex I, and complex II activity, which might have resulted from elevated mitochondrial calcium uptake. The alterations in the mitochondrial calcium uptake and mitochondrial electron transfer enzyme activities in turn might have caused an increase in malondialdehyde, protein carbonyl and 8hydoxydeoxyguanosine formation as a result of enhanced lipid peroxidation, and as well as protein and mtDNA oxidation. All this could have been because of enhanced oxidative stress, decreased GSH levels and also decreased Mn-SOD activity in the mitochondria isolated from dichlorvos treated rat brain. Thus, chronic organophosphate exposure has the potential to disrupt cellular antioxidant defense system which in turn triggers the release of cytochrome $\mathrm{c}$ from mitochondria to cytosol as well as caspase-3 activation in dichlorvos treated rat brain Low-level long-term organophosphate exposure finally resulted in oligonucleosomal DNA fragmentation, a hallmark of apoptosis. These studies provide an evidence of impaired mitochondrial bioenergetics and apoptotic neuronal degeneration after chronic low-level exposure to OPs that affect the behavioural impairement (Kaur et al., 2007). OPs can also modulate intracellular signaling pathways downstream of receptors and suggests that the diverse neurotoxic effects of many Ops may reflect their influence on multiple intracellular signaling pathways. Functional studies examining the effects of OPs on signaling events downstream of muscarinic receptor activation further support the hypothesis that OPs can interact directly with M2 receptors (Verma et al., 2008). A comparative study of paraoxon, malaoxon, and chlorpyrifos oxon in slice cultures of rat frontal cortex indicated that all three OPs inhibited cAMP formation in a concentration dependent manner (Ward and Mundy., 1996). Chlorpyrifos-oxon was also found to inhibit c-AMP synthesis in striatal dissociated cells (Huff et al., 1994).

Numerous studies have indicated that CREB is critical to several forms of use-dependent synaptic plasticity and transcription-dependent forms of memory, and evidence supports a major role for CREB in cell survival and differentiation during brain development. Since impairments of brain development and memory function are two primary neurological effects observed in laboratory studies with OPs, Schuh et al., (2002) hypothesized that the mechanisms underlying these effects may include alteration of the expression or activational status of CREB. Verma et al.,(2008) reported dichlorvos at low dose exposure, leads to reduction in the signal transduction cascade linked to receptor subtypes and adenylyl cyclase-linked signaling pathway was impaired. Finally, the phosphorylation of CREB, was significantly reduced in both low dose and high dose group animals. These reveal the significance of M2 muscarinic receptor linked adenylyl cyclase signaling pathway and phosphorylation of CREB in the development of neurobehavioral impairments after chronic low-level exposure to dichlorvos.

\section{Developmental toxicity}

Although some organophosphates are undergoing increasing scrutiny and restriction (U.S. Environmental Protection Agency (EPA) 2000, 2002) because of their propensity to elicit developmental neurotoxicity ( Casida and Quistad2004; Landrigan 2001; Slotkin 2004), these compounds nevertheless still comprise $50 \%$ of all insecticide use worldwide, and exposure of the human population continues to be nearly ubiquitous (Casida and Quistad 2004). Originally, it was thought that the adverse effects on brain development reflected the same 
basic mechanism that underlies systemic toxicity, namely, cholinesterase inhibition and consequent cholinergic hyperstimulation (Pope 1999). However, evidence accumulating over the past decade implicates a host of other mechanisms that depend instead upon the direct targeting of events specific to the developing brain (Barone et al. 2000; Pope 1999; Rice and Barone 2000; Slotkin 2004). Levels of pesticides detected in amniotic fluid demonstrate that the foetus has direct exposure to at least some pesticides during development (Bradman2003). Chlorpyrifos, the most-studied organophosphate, has been shown to disrupt the basic cellular machinery that controls the patterns of neural cell maturation and the formation and activity of synapses, exclusive of the effects on cholinesterase, which are mediated instead by its metabolite, chlorpyrifos oxon (Barone et al. 2000; Casida and Quistad 2004; Gupta 2004; Pope 1999; Qiao et al. 2002, 2003; Yanai et al. 2002). These mechanisms are likely to be shared by other organophosphates, but these have not been evaluated in detail (Abu-Qare and Abou-Donia 2001; Pope 1999; Qiao et al. 2001; Slotkin 1999, 2004; Whyatt et al. 2002). Chlorpyrifos exposure during the perinatal period is known to evoke deficits in neuritic outgrowth, specifically including the targeting of cholinergic projections (Howard et al. 2005; Qiao et al. 2002, 2003; Slotkin et al. 2001). Nevertheless, (Dam et al.1999), as early as 1 day after neonatal chlorpyrifos exposure, there is a shortfall in ChAT, the constitutive marker of cholinergic projections (Dam et al.1999). The initial deficits in the development of cholinergic projections lead to the subsequent emergence of abnormalities of cholinergic innervation. Substantial deficits in cholinergic synaptic activity, and related behavioral anomalies in adolescence and adulthood (2001; Slotkin 1999,2001, 2004; Slotkin et al. 2001).

Young animals are far more susceptible than adults to organophosphate-induced growth inhibition and lethality, there is a wide range over which disparate compounds elicit such effects. For example, parathion is far more systemically toxic to newborn rats than is chlorpyrifos, in part reflecting pharmacokinetic differences centering around the ontogeny of enzymes activating the parent compounds to the corresponding oxons, compared with the enzymes that break down the oxons to inactive metabolites (Atterberry et al. 1997; Padilla et al. 2000, 2004). The maximum tolerated doses of each agent correspond closely to the relative potencies toward cholinesterase inhibition and to the rate of recovery of cholinesterase activity, thus drawing a direct mechanistic connection of cholinergic hyperstimulation to overall systemic toxicity (Pope and Chakraborti 1992; Pope et al. 1991; Tang et al. 2003). In contrast, in vitro evaluations that bypass the pharmacokinetic differences suggest that chlorpyrifos is more potent toward inhibition of cell membrane function (Barber et al. 2001) and for eliciting cytotoxicity in immature neurons and glia (Monnet-Tschudi et al. 2000), despite the fact that parathion elicits greater cholinesterase inhibition (Zurich et al. 2000); indeed, physostigmine, a nonorganophosphate cholinesterase inhibitor, is far less effective in disrupting neural cell development in vitro, even at concentrations that completely block cholinesterase (Qiao et al. 2001). Theodore et al, (2006) studied the neuritic outgrowth and cholinergic synaptic development in neonatal rats. They have given different organophosphates (chlorpyrifos, diazinon, parathion) at doses spanning the threshold for impaired growth and viability. The result indicated that Parathion (maximum tolerated dose, $0.1 \mathrm{mg} / \mathrm{kg}$ ) was far more systemically toxic than was chlorpyrifos or diazinon (maximum tolerated dose, $1-5 \mathrm{mg} / \mathrm{kg}$ ). Below the maximum tolerated dose, diazinon impaired neuritic outgrowth in the forebrain and brainstem, evidenced by a deficit in the ratio of membrane protein to total protein. Diazinon also 
decreased choline acetyltransferase activity, whereas it did not affect hemicholinium-3 binding to the presynaptic choline transporter, an index of cholinergic neuronal activity. These results indicate a complete dichotomy between the systemic toxicity of organophosphates and their propensity to elicit developmental neurotoxicity.

Brenda Eskenazi et al (2007) investigated the relationship of prenatal and child OP urinary metabolite levels with children's neurodevelopment. Their result indicated, dialkylphosphate (DAP) levels were negatively associated with Mental Development ( MDI), but child measures were positively associated. At 24 months of age, these associations reached statistical significance. Neither prenatal nor child DAPs were associated with Child Behavior Checklist (CBCL) attention problems, but both prenatal and postnatal DAPs were associated with risk of pervasive developmental disorder. Their report revealed adverse associations of prenatal DAPs with mental development and pervasive developmental problems at 24 months of age. Results should be interpreted with caution given the observed positive relationship with postnatal DAPs. Raul Harari et al (2010), studied Northern Ecuador population, where floriculture is intensive and relies on female employment, they carried out an intensive cross-sectional study to assess children's neurobehavioral functions at 6-8 years of age. They examined all 87 children attending two grades in the local public school with an expanded battery of neurobehavioral tests. Information on pesticide exposure during the index pregnancy was obtained from maternal interview. The children's current pesticide exposure was assessed from the urinary excretion of organophosphate metabolites and erythrocyte acetylcholine esterase activity. Their findings support the notion that prenatal exposure to pesticides at levels not producing adverse health outcomes in the mother can cause lasting adverse effects on brain development in children. Pesticide exposure therefore may contribute to a "silent pandemic" of developmental neurotoxicity (Raul Harari et al ,2010).

\section{Role of paraoxonase in OP detoxication}

In 1946, Abraham Mazur was the first to report the presence of an enzyme in animal tissue which was able to hydrolyse organophosphate compounds (Mazur,1946). This led to the initial identification of the human serum paraoxonase (PON1) enzyme in the early 1950s (Aldridge,1951a, Aldridge,1951b). PON1 was named after its ability to hydrolyse the organophosphate substrate paraoxon (paraoxonase activity, EC 3.1.8.1), which is the toxic metabolite of the insecticide parathion. Because PON1 could also hydrolyse aromatic esters, such as phenylacetate (arylesterase activity, EC 3.1.1.2), the term 'A-esterase' was introduced for the enzyme hydrolysing both compounds. This led to much discussion during the following years as to whether one enzyme or two were responsible for the paraoxonase and arylesterase activity, ( La Du ,2002) but finally, conclusive evidence was delivered that both paraoxonase activity and arylesterase activity were properties of PON1. (Sorenson 1995) When Mackness and colleagues demonstrated that PON1 could prevent the accumulation of lipoperoxides in low-density lipoprotein (LDL) (Mackness,1991) thus linking PON1 to cardiovascular disease, the scientific interest in PON1 increased immensely. Despite the boom in research, to date the exact physiological function of PON1 is still unclear.

PON1 belongs to a family of serum paraoxonases, consisting of PON1, PON2 and PON3. The genes coding for these enzymes are all located next to each other on the long arm of chromosome (Primo-Parmo,1996) (7q21.3-q22.1)7. PON1 and PON3 are expressed in the liver and excreted in the blood where they are associated with the high-density lipoprotein 
(HDL) particle( Reddy ,2001). PON2 is not present in blood, but is expressed widely in a number of tissues, including the liver, lungs, brain and heart (Mochizuki 1998). Of the paraoxonase family, PON1 is the most investigated and best understood member. While it was assumed that high levels of PON1 would protect against exposure to specific OP compounds, only a single experiment that directly addressed this question had been reported prior to 1990. Main (1956) reported that injection of partially purified PON1 into rats increased their resistance to paraoxon. This observation was confirmed and extended through a series of experiments begun in costa et al laboratory in 1990. Injection of purified rabbit paraoxonase into rats increased their resistance to paraoxon exposure (Costa et al., 1990). Injection of purified rabbit PON1 into mice $4 \mathrm{~h}$ prior to exposure dramatically increased their resistance to chlorpyrifos oxon (Li et al., 1993). An increase in resistance to the parent compound, chlorpyrifos, was also observed (Li et al., 1995). These experiments demonstrated clearly that high levels of plasma paraoxonase could protect against exposure to chlorpyrifos oxon or chlorpyrifos. Protection was also observed when purified rabbit PON1 was injected post-exposure or $24 \mathrm{~h}$ prior to exposure, indicating that administration of purified or recombinant PON1 would be useful for ameliorating or even preventing adverse consequences of exposure to OP compounds. Whereas higher PON1 levels were demonstrated clearly to be protective, determining whether low levels of PON1 would result in greater sensitivity was not possible until the development of PON1knockout mice, generated by Drs. Jake Lusis, Diana Shih and co-workers (Shih et al., 1998). Knocking out the mouse PON1 gene resulted in a dramatic increase in sensitivity to chlorpyrifos oxon exposure and a modest increase in sensitivity to chlorpyrifos exposure, as assessed by measuring brain cholinesterase inhibition. Dermal exposures to levels of chlorpyrifos oxon that produced no symptoms of cholinergic effects and minimal inhibition of brain cholinesterase in wild-type mice were unexpectedly lethal to the PON1 null mice. Similar results were observed when the knockout mice were exposed to diazoxon (Li et al., 2000). Dermal exposure to 2 or $4 \mathrm{mg} / \mathrm{kg}$ diazoxon produced no measurable effect in wild-type mice, but was lethal to the PON1 knockout mice, and exposure to $1 \mathrm{mg} / \mathrm{kg}$ diazoxon had significant adverse effects in the knockout mice without measurably affecting the wild-type mice. Hemizygous mice, with only one PON1 allele, exhibited intermediate sensitivity. Exposure of the PON1 knockout mice to paraoxon, however, produced an unexpected and initially puzzling result. They were not anymore sensitive than wild-type mice to paraoxon exposure. Further experiments demonstrated that resistance of the PON1 knockout mice to diazoxon was restored by injection of purified PON1R192 or PONQ192 alloforms, with either alloform providing equivalent protection ( $\mathrm{Li}$ et al., 2000). Resistance to chlorpyrifos oxon was also restored; however, the PON1R192 alloform provided significantly better protection that did the PON1Q192 alloform. Neither alloform provided protection against paraoxon exposure. While there was some protection afforded by PON1 against the respective parent compounds, the protective effects of PON1 were most striking with the oxonforms of chlorpyrifos and diazinon. The parent OP compound is converted to its more toxic oxon form in the liver, by cytochrome P450-mediated oxidative desulfuration, and the oxon form serves as the direct substrate for PON1. Since chlorpyrifos oxon inhibits acetylcholinesterase at least 1000 times more rapidly than chlorpyrifos (Huff et al., 1994), even a small percentage of oxon content is important with respect to an individual's PON1 status

Multiple investigators have examined the potential role of polymorphisms in veterans with unexplained illness, but the results have been mixed (Haley et al1999). Haley et al (1999) 
reported that the most severely symptomatic GW veterans exhibited particularly low activity of paraoxonase (PON1) type $Q$, the type that would be most active in neutralizing nerve gases. Mackness et al, (2000) found that veteran's decreased capacity to metabolize OP chemicals might have contributed to their likelihood of developing GW illness. Hotoph et al (2003) found that PON1 activity, which is a major determinant of OP toxicity in human, was significantly decreased in British veterans deployed to the GW compared to nondeployed veterans. The PON1 gene presents several polymorphisms in the coding and promoter regions that affect the catalytic efficiency of the enzyme toward different substrates (the Q192R polymorphism) and its level of expression (e.g., the C-108T polymorphism). Extensive research in transgenic animal models clearly indicates that PON1 "status", encompassing both the Q192R polymorphism and the level of PON activity, plays a most relevant role in modulating the acute toxicity of some, but not all OPs. The important determinant is the catalytic efficiency of each PON1 allozyme toward a specific substrate; thus, in case of chlorpyrifos oxon, PON1 provides protection in vivo, and PON1R192 provides better protection than PON1Q192; in case of diazoxon, both alloforms provide the same degree of protection, while in case of paraoxon, the substrate after which the enzyme was named, PON1 does not provide any protection due to an overall low catalytic efficiency of PON1 toward this substrate. These studies in transgenic mice provide a convincing case of extrapolating the results obtained in animals to humans; however, direct and conclusive confirmation of the relevance of PON1 status in determining relative susceptibility to OP toxicity is still lacking.

\section{Conclusions}

This chapter covers the background information and the epidemiological evidence, on exposures of people and different experimental animals to pesticide and the consequences in regard to the neurodegeneration, neurodevelopment and neurobehavioral impairments. The fact that different studies provide equivocal results on the functions affected, together with the fact that the observed changes are usually very high, and do appear to be correlated with overt nervous system impairment, suggest that the neurobehavioural impact of low level prolonged exposure to pesticides. In addition to that pesticide exposure also affects the offspring, and consistent neurobehavioral impairments were also reported. The evidence suffers from a variety of shortcomings and sources of imprecision. These problems would tend to cause an underestimation of the true extent of the risks. The overall experimental and epidemiological evidence suggests that the substantial vulnerability of the mature and developing nervous system to low concentrations of pesticides should lead to a strengthened emphasis on protection of workers and general people who handle the pesticides that may cause harm to the nervous system. For both toxicologic and epidemiologic reasons, it is essential that the neurobehavioral potential of low-level, chronic exposure to pesticides and pesticide mixtures be ascertained. The available evidence suggests there is a high probability for subtle adverse health effects. Workers exposed to pesticides are one of the largest occupational risk groups in the world. The effects of these occupational exposures on worker's nervous systems and behaviour are just beginning to be studied. A precautionary principle in regard to neuronal toxicity should be applied in occupational health, and this issue should also attract more research, preferably with a focus on exposure assessment and valid outcome measures in prospective study designs. 
PON1 status plays an important role in protecting against exposures to diazinon and chlorpyrifos, particularly to the oxon residues present in these exposures. The most important conclusion to come from studies is that to understand the role that PON1 plays in an individual's sensitivity or resistance to a given exposure or in the pharmacokinetic disposition of a specific drug, it is important to know both the levels of PON1 and it's genetic polymorphism. This too is expected to be a fruitful area of future research. In conclusion, we found that prevalence of neurologic symptoms was associated with exposure to pesticides. These associations were present in individuals with no history of pesticide poisoning or high exposure events and were independent of recent exposure. Thus, they are likely due to chronic moderate exposure. Although the neurotoxicity of high-level exposure is accepted, more attention to the risks associated with moderate low level exposure may be required. Research is needed to improve our understanding of the mechanisms involved and help in identifying the best means of protecting future generations against a silent pandemic of neurotoxicity.

\section{References}

Abou-DoniaMB. Organophosphorus ester-induced chronic neurotoxicity. Arch Environ Health 2003;58:484-97.

Abu-Qare AW, Abou-Donia MB. Inhibition and recovery of maternal and fetal cholinesterase enzyme activity following a single cutaneous dose of methyl parathion and diazinon, alone and in combination, in pregnant rats. J Appl Toxicol 2001; 21:307-316.

Aiuto, L. A., Pavlakis, S. G., and Boxer, R. A. Life-threatening organophosphate-induced delayed polyneuropathy in a child after accidental chlorpyrifos ingestion. J. Pediatr. 1993;122, 658-660.

Aldridge WN. Serum esterases. I. Two types of esterase (A and B) hydrolysing pnitrophenyl acetate, propionate and butyrate, and a method for their determination. Biochem J 1951b;51:110-7.

Aldridge WN. Serum esterases. II. An enzyme hydrolysing diethyl p-nitrophenyl phosphate (E600) and its identity with the A-esterase of mammalian sera. Biochem J 1951a;51:117-24.

Amr MM, Halim ZS, Moussa SS. Psychiatric disorders among Egyptian pesticide applicators and formulators. Environ Res 1997;73:193-9.

Anger WK, Liang YX, Nell V, Kang SK, Cole D, Bazylewicz-Walczak B, et al. Lessons learned - 15 years of theWHO-NCTB: a review. Neurotoxicology 2000;21:837-46.

Atterberry TT, Burnett WT, Chambers JE. Age-related differences in parathion and chlorpyrifos toxicity in male rats:target and nontarget esterase sensitivity and cytochrome P450-mediated metabolism. Toxicol Appl Pharmacol.1997; 147:411418.

Baker EL, Letz R, Fidler A. A computer-administered neurobehavioral evaluation system for occupational and environmental epidemiology: Rationale, methodology, and pilot study results. J Occup Med.1985; 27(3):206-212.

Barber D, Hunt J, Ehrich M. Inhibition of calcium-stimulated ATPase in the hen brain P2 synaptosomal fraction by organophosphorus esters: relevance to delayed neuropathy. J Toxicol Environ Health.2001; 63:101-113. 
Barone S, Das KP, Lassiter TL, White LD.Vulnerableprocesses of nervous system development: a review ofmarkers and methods. Neurotoxicology.2001; 21:15-36

Barr DB, Allen R, Olsson AO, Bravo R, Caltabiano LM,Montesano A, et al. Concentrations of selective metabolites of organophosphorus pesticides in the United States population. Environ Res 2005;99:314-26.

Bhatt, M.H., Elias, M.A., and Mankodi, A.K. Acute and reversible parkinsonism due to organophosphate pesticide intoxication: Five cases. Neurology 1999; 52, 1467-1471.

Binukumar BK, Bal A, Kandimalla RJ, Gill KD. Nigrostriatal neuronal death following chronic dichlorvos exposure: crosstalk between mitochondrial impairments, a synuclein aggregation, oxidative damage and behavioral changes. Mol Brain. 2010; 13;3:35.

BL, Hicks K. Neurobehavioral evaluation of soil and structural fumigators using methyl bromide and sulfuryl fluoride. Neurotoxicology.1986; 7(3): 137-156.

Bradman A, Barr DB, Claus Henn BG, Drumheller T, Curry C, Eskenazi B. Measurement of pesticides and other toxicants in amniotic fluid as a potential biomarker of prenatal exposure: a validation study. Environmental Health Perspectives 2003;111:1779-82.

Brenda Eskenazi, Amy R. Marks, Asa Bradman, Kim Harley, Dana B. Barr, Caroline Johnson, Norma Morga, and Nicholas P. JewellOrganophosphate Pesticide Exposure and Neurodevelopment in Young Mexican-American Children. Environmental Health Perspectives.2007;115(5) 792-798.

Brown, M.A., and Brix, K.A. Review of health consequences from high-, intermediate-, and low-level exposure to organophosphorus nerve agents. J. Appl. Toxicol.1998; 18, 393-408.

Burkhart JA, Gehrich JL, Smith TJ, Segura RP, Turner ER (1978): Assessment of measurement techniques for worker exposure to pesticides. NIOSH Contract No. 210-76-0153.

Casida JE, Quistad GB.Organophosphate toxicology: safety aspects of nonacetylcholinesterase secondary targets.Chem Res Toxicol.2004; 17:983-998

Cassitto MG, Camerino D, Hanninen H, Anger WK. International collaboration to evacuate the WHO neurobehavioral core test battery. In: Johnson BL, Anger WK, Duran A, Xintaras C, editors. Advances in neurobehavioral toxicology: applications in environment and occupational health. Chelsea, MI:Lewis;1990. p. 203-23.

Colosio C, Tiramani M, Brambilla G, Colombi A, Moretto A. Neurobehavioural effects of pesticides with special focus on organophosphorus compounds: which is the real size of the problem? Neurotoxicology 2009;30:1155-61.

Colosio C, TiramaniM,MaroniM. Neurobehavioral effects of pesticides: state of the art. Neurotoxicology 2003;24:577-91.

Costa LG, McDonald BE, Murphy SD, Richter RJ, Motulsky AG, Furlong CE. Serum paraoxonase and its influence on paraoxon and chlorpyrifos oxon toxicity in rats. Toxicol Appl Pharmacol 1990;103:66-76.

Dam K, Garcia SJ, Seidler FJ, Slotkin TA. Neonatal chlorpyrifos exposure alters synaptic development and neuronal activity in cholinergic and catecholaminergic pathways. Dev Brain Res.1999; 116:9-20.

Das R, Steege A, Baron S, Beckman J, Harrison R. Pesticide-related illness among migrant farm workers in the United States. Int J Occup \& Environ Health 2001;7:303-12 
Durham WF, Wolfe HR, Quinby GE. Organophosphorus insecticides and mental alertness. Arch Environ Health.1965; 10:55-66.

Farahat FM, Fenske RA, Olson JR, Galvin K, Bonner MR, Rohlman DS, et al. Chlorpyrifos exposures in Egyptian cotton field workers. Neurotoxicology 2010;31:297-304.

Fiedler N, Feldman RG, Jacobson J, Rahill A, Wetherell A. The assessment of neurobehavioral toxicity: SGOMSEC joint report. Environ Health Perspect 1996;104(Suppl 2):179-91.

Freya Kamel, Lawrence S. Engel, Beth C. Gladen, Jane A. Hoppin, Michael C. R. Alavanja, and Dale P. Sandler. Neurologic Symptoms in Licensed Private Pesticide Applicators in the Agricultural Health Study. Environ Health Perspect.2005; 113:877-882.

Gershon S, Shaw FH. Psychiatric sequelae of chronic exposure to organophosphorus insecticides. Lancet i:1961; 1371-1374.

Gralewicz S, Soćko R. Persisting behavioural and electroencephalographic effects of exposure to chlorphenvinphos, an organophosphorous pesticide, in laboratory animals. Int J Occup Med Environ Health. 1997;10(4):375-94.

He F. Synthetic pyrethroids. In: Tordoir WF, Maroni M, He F, editors. Health surveillance of pesticide workers. A manual for occupational health professionals. Toxicology [special issue] 1994;43-50.

Hotopf M, Mackness MI, Nikolaou V, Collier DA, Curtis C, David A, Durrington P, Hull L, Ismail K, Paraoxonase in Persian Gulf War veterans. J Occup Environ Med. 2003 Jul;45(7):668-75.

Howard AS, Bucelli R, Jett DA, Bruun D, Yang DR. Chlorpyrifos exerts opposing effects on axonal and dendritic growth in primary neuronal cultures. Toxicol Appl Pharmacol. 2005; 207:112-124.

Huff RA, Corcoran JJ, Anderson JK, Abou-Donia MB. Chlorpyrifos oxon binds directly to muscarinic receptors and inhibits cAMP accumulation in rat striatum. J Pharmacol Exp Ther 1994;269:329-35.

Huff, R.A., and Abou-Donia, M.B. Cis-Methyldioxolane specifically recognizes the $\mathrm{m} 2$ muscarinic receptor.J Neurochem.1994: 62: 388-391.

Institute of Medicine. Health Consequences of Service During the Persian Gulf War: Initial Findings and Recommendations for Immediate Action. Washington, DC: 1996 National Academy Press.

International Programme on Chemical Safety (IPCS). Environmental health criteria 223. Neurotoxicity risk assessment for human health: principles and approaches. Geneva: World Health Organization (WHO); 2001 ISBN 944157223 X.

Iowa Persian Gulf Study Group. Self-reported illness and health status among Gulf War veterans: a population-based study. JAMA.1997; 277:238-245.

Jamal, G.A. Neurological syndromes of organophosphorus compounds. Adverse Drug React. Toxicol. Rev.1997 16, 133-170.

Jayawardane P, Senanayake N, Dawson A. Electrophysiological correlates of intermediate syndrome following acute organophosphate poisoning. Clin Toxicol (Phila) 2009;47:193-205

Jeyaratnam J, Maroni M. Organophosphorous compounds. In: Tordoir WF, Maroni M, He F, editors. Health surveillance of pesticide workers. A manual for occupational health professionals. Toxicology [special issue] 1994;15-28. 
Johnson BL, Anger WK (1983): Behavioral toxicology. In Rom WN (Ed): “Environmental and Occupational Medicine. "Boston: Little Brown and Company.

Kaur, P., Ranjana, B., Minz, W., and Gill, K.D. Impaired mitochondria energy metabolism and Neuronal apoptotic cell death after Chronic Dichlorvos (OP) Exposure in rat brain. Neurotoxicology.2007; 28: 1208-1219.

Korsak RJ, Sato MM. Effects of chronic organophosphate pesticide exposure on the central nervous system. Clin Toxicol.1977; 11:83-95.

Krasnegor NA, Otto DA, Bernstein JH, Burke R, Chappell W, Eckerman DA, et al.Neurobehavioral test strategies for environmental exposures in pediatric populations. Neurotoxicol Teratol 1995;16(5):499-509

La Du B. Historical Considerations. In: Costa LG, Furlong CE (eds). Paraoxonase (PON1) in health and disease: basic and clinical aspects. Berlin: Kluwer academic publishers, 2002 1-25.

Landrigan PJ. Pesticides and polychlorinated biphenyls (PCBs): an analysis of the evidence that they impair children's neurobehavioral development. Mol Genet Metab.2001; 73:11-17.

Lessenger, J., and Reese, B.E. Rational use of cholinesterase activity testing in pesticide poisoning. J. Am. Board. Fam. Pract.1999; 12, 307-334.

Levin HS, Rodnitzky RL. Behavioral effects of organophosphate pesticides in man. Clin Toxicol.1976; 9: 391-405.

Levin, HS., Rodnitky, R.L., and Mick, D.L. Anxiety associated with exposure to organophosphate compounds. Arch. Gen. Psych.1976; 33, 225-228.

Li WF, Costa LG, Richter RJ, Hagen T, Shih DM, Tward A, et al. Catalytic efficiency determines the in vivo efficacy of PON1 for detoxifying organophosphates. Pharmacogenetics 2000;10:1-13.

Li WF, Furlong CE, Costa LG. Paraoxonase protects against chlorpyrifos toxicity in mice. Toxicol Lett 1995;76:219-26.

London L, Myers JE, Nell V, Taylor T, Thompson ML. An investigation into neurologic and neurobehavioral effects of long-term agrichemical use among deciduous fruit farm workers in the Western Cape, South Africa. Environ Res 1997;73:132-45.

Lotti M, Moretto A. Organophosphate induced delayed polyneuropathy. Tox Rev 2005;24:37-49.

Lotti M. Clinical toxicology of anticholinesterase agents. In: Krieger R, editor. Handbook of pesticide toxicology 2nd ed. San Diego: Academic Press; 2001 1043-85.

Machemer LH, Pickel M. Carbamate insecticides. In: Tordoir WF,Maroni M, He F, editors. Health surveillance of pesticide workers. A manual for occupational health professionals. Toxicology [special issue] 1994;29-36.

Mackness B, Durrington PN, Mackness MI. Low paraoxonase in Persian Gulf War Veterans self-reporting Gulf War Syndrome. Biochem Biophys Res Commun. 2000:24;276(2):729-33.

Mackness MI, Arrol S, Durrington PN. Paraoxonase prevents accumulation of lipoperoxides in low-density lipoprotein. FEBS Lett 1991;286:152-4.

Main AR. The role of A-esterase in the acute toxicity of paraoxon, TEPP and parathion. Can J Biochem Physiol 1956;34:197-216.

Mazur A. An enzyme in animal tissues capable of hydrolyzing the phosphorus-fluorine bond of alkyl fluorophospates. J Biol Chem 1946; 164:27-89. 
Metcalf DR, Holmes JH. EEG, psychological and neurological alterations in humans with organophosphate exposure. Ann NY Acad Sci.1969; 160:357-365.

Mileson, BE., Chambers, JE., Chen, WL., Dettbarn, W., Ehrich, M.,Eldefrawi, AT., Gaylor, DW and Wallace, KB. Common mechanism of toxicity: A case study of organophosphorus pesticides. Toxicol. Sci.1998; 41, 8-20.

Monnet-Tschudi F, Zurich MG, Schilter B, Costa LG, Honegger P. Maturation-dependent effects of chlorpyrifos and parathion and their oxygen analogs on acetylcholinesterase and neuronal and glial markers in aggregating brain cell cultures. Toxicol Appl Pharmacology.2000; 165:175-183

Moser VC. Animal models of chronic pesticide neurotoxicity. Hum Exp Toxicol 2007;26(4):321-31.

Neil Maizlish Marc Schenker Carol Weisskopf James Seiber Steven Samuels. A behavioral evaluation of pest control workers with short-term, low-level exposure to the organophosphate diazinon. American Journal of Industrial Medicine.1987; 12,e 2,153-172.

Padilla S, Buzzard J, Moser VC. Comparison of the role of esterases in the differential age-related sensitivity to chlorpyrifos and methamidophos. Neurotoxicology.2000; 21:49-56.

Padilla S, Sung HJ, Moser VC. Further assessment of an in vitro screen that may help identify organophosphorus pesticides that are more acutely toxic to the young. J Toxicol Environ Health.2004; 67:1477-1489.

Persian Gulf Veterans Coordinating Board. Unexplained illnesses among Desert Storm veterans. Arch Int Med.1995; 155:262 268 .

Peter, J.V., and Cherian, A. M. Organic insecticides. Anaesth. Intensive Care.2000; 28, 11-21.

Pope CN, Chakraborti TK, Chapman ML, Farrar JD, Arthun D. Comparison of in vivo cholinesterase inhibition in neonatal and adult rats by three organophosphorothioate insecticides. Toxicology.1991; 68:51-61.

Pope CN, Chakraborti TK. Dose-related inhibition of brain and plasma cholinesterase in neonatal and adult rats following sublethal organophosphate exposures. Toxicology.1992; 73:35-43.

Pope CN. Organophosphorus pesticides: do they all havethe same mechanism of toxicity? J Toxicol Environ Health.1999; 2:161-181.

Proctor SP, Heeren T, White RF, Wolfe J, Borgos MS, Davis JD, Pepper L, Clapp R, Sutker PB, Vasterling JJ, Ozonoff D. Health status of Persian Gulf War veterans: selfreported symptoms, environmental exposures, and the effect of stress. Int J Epidemiol.1998; 27:1000- 1010.

Qiao D, Seidler FJ, Slotkin TA. Developmental neurotoxicity of chlorpyrifos modeled in vitro: comparative effects of metabolites and other cholinesterase inhibitors on DNA synthesis in PC12 and C6 cells. Environ Health Perspect.2001; 109:909-913.

Rastogi, S Tripathi, D Ravishanker. A study of neurologic symptoms on exposure to organophosphate pesticides in the children of agricultural workers. JOEM 2010: 14: 2: 54-57.

Raul Harari, Jordi Julvez, Katsuyuki Murata, Dana Barr, David C. Bellinger, Frodi Debes,and Philippe Grandjean. Neurobehavioral Deficits and Increased Blood Pressure in School-Age Children Prenatally Exposed to Pesticides. Environmental Health Perspectives.2010;118 (6) :890-896 
Ray, DE., and Richards, PG. The potential for toxic effects of chronic, low-dose exposure to organophosphates. Toxicol. Teratol.2001; 120, 343-351.

Reddy ST, Wadleigh DJ, Grijalva V, et al. Human paraoxonase-1 is an HDL-associated enzyme with biological activity similar to paraoxonase-1protein but is not regulated by oxidized lipids. Arterioscler Thromb Vasc Biol 2001;21:542-7.

Redhead IH. Poisoning on the farm. Lancet.1968 1:686-688.

Rice D, Barone SJ. Critical periods of vulnerability for the developing nervous system: evidence from human and animal models. Environ Health Perspect 2000;108: 51133.

Rodnitzky RL, Levin HS, Mick DL. Occupational exposure to organophosphate pesticides. Arch Environ Health 1975;30:98-103.

Sarin S, Gill KD. Biochemical and behavioral deficits in adult rat following chronic dichlorvos exposure. Pharmacol Biochem Behav. 1998;59(4):1081-6.

Savage EP, Keefe TJ, Mounce LM, Lewis JA, Heaton RK, Parks LH. “Chronic Neurological Sequelae of Acute Organophosphate Pesticide Poisoning: An Epidemiologic Study. Final Report.1982 " Fort Collins: Colorado Epidemiologic Pesticide Studies Center.

Senanayake, N., and Johnson, MK. Acute polyneuropathy after poisoning by a new organophosphate insecticide. N. Eng. J. Med.1982; 306, 155-157.

Shahar, E., and Andraws, J. Extra-pyramidal parkinsonism complicating organophosphate insecticide poisoning. Eur. J. Paediatr. Neurol.2001; 5, 261-264.

Shih DM, Gu L, Xia YR, Navab M, Li WF, Hama S, et al. Mice lacking serum paraoxonase are susceptible to organophosphate toxicity and atherosclerosis. Nature 1998;394:284-7

Slotkin TA. Cholinergic systems in brain development and disruption by neurotoxicants: nicotine, environmental tobacco smoke, organophosphates. Toxicol Appl Pharmacol.2004; 198:132-151.

Smith PW, Stavinoha WB, Ryan LC. Cholinesterase inhibition in relation to fitness to fly. Areospace Med.1968; 39:754-758.

Sorenson RC, Primo-Parmo SL, Kuo CL, Adkins S, Lockridge O, La Du BN. Reconsideration of the catalytic center and mechanism of mammalian paraoxonase/arylesterase. Proc Natl Acad Sci U S A 1995;92:7187-91

Stephens R, Spurgeon A, Calvert IA, Beach J, Levy LS, Berry H, et al. Neuropsychological effects of long-term exposure to organophosphates in sheep dip. Lancet 1995;345:1135-9.

Sudakin, D. L., Mullins, M. E., Horowitz, B. Z., Abshier, V., and Letzig, L. Intermediate syndrome after malathion ingestion despite continuous infusion of pralidoxime. J. Toxicol. Clin. Toxicol. 2000;38, 47-50.

Tang J, Carr RL, Chambers JE. The effects of repeated oral exposures to methyl parathion on rat brain cholinesterase and muscarinic receptors during postnatal development. Toxicol Sci.2003; 76:400-406.

Theodore A. Slotkin, Edward D. Levin, and Frederic J. Seidler. Comparative Developmental Neurotoxicity of Organophosphate Insecticides:Effects on Brain Development Are Separable from Systemic Toxicity. Environmental Health Perspectives.2006; 114, 5.746-751. 
Tordoir WF, Van Sittert NJ. Organochlorines. In: Tordoir WF, Maroni M, He F, editors. Health surveillance of pesticide workers. A manual for occupational health professionals. Toxicology [special issue] 1994;51-8.

U.S. EPA (U.S. Environmental Protection Agency). 2000. Administrator's Announcement. Available: http://www.epa.gov/pesticides/announcement6800.htm [accessed13 October 2004].

U.S. EPA (U.S. Environmental Protection Agency). 2002.Chlorpyrifos: End-Use Products Cancellation Order.Available: http://www.epa.gov/fedrgstr/EPAPEST/2002/January/Day-25/p1764.htm [accessed 6 December 2004].

US Environmental Protection Agency. Pesticides industry sales and usage: 2000 and 2001 market estimates. 2004. http://www.epa.gov/oppbead1/pestsales/. Kiely T, Donaldson D, Grube A. Pesticides industry sales and usage: 2000 and 2001 market estimates. EPA-733-R-04-001. Washington, DC: Office of Pesticide Pro-grams, U.S. Environmental Protection Agency. 2004. Available: http://www.

Verma, S.K., Raheja, G., Ranjana, B., Minz, W., and Gill, K.D. Role of muscarinic signal transduction and CREB phosphorylation in dichlorvos-induced memory deficits in rats: An acetylcholine independent mechanism. Toxicology, 2009: 27;256(3):175-82.

Ward, TR., and Mundy, WR. Organophosphorus compounds preferentially affect second messenger systems coupled to M2/M4 receptors in rat frontal cortex. Brain Res Bull.1996: 39: 49-55.

Wetherell A. The assessment of neurobehavoral toxicity: SGOMSEC joint report. Environ Health Perspect (Suppl. 2):1996;179-81.

Whyatt RM, Camann DE, Kinney PL, Reyes A, Ramirez J, Dietrich J, et al. Residential pesticide use during pregnancy among a cohort of urban minority women. Environ Health Perspect.2002; 110:507-514.

Wolfe J, Proctor SP, Duncan Davis J, Borgos MS, Friedman MJ. 1998. Health symptoms reported by Persian Gulf War veterans two years after return. Am J Ind Med 33:104-113.

Wood WW, Brown HW, Watson M, Benson WW. Implication of organophosphate pesticide poisoning in the plane crash of a duster pilot. Aerospace Med.1971 42:1111-1113.

Xintaras C, Burg JB, Tanaka S, Lee ST, Johnson BL, Cottrill CA, Bender J : "NIOSH Health Survey of Velsicol Pesticide Workers."1978; DHEW (NIOSH) Pub1 No 78-136.

Xue SZ, Loosly R. Formamidines. In: Health surveillance of pesticide workers. A manual for occupational health professionals. Tordoir WF, Maroni M, He F, editors. Toxicology [special issue] 1994;99-104.

Yanai J, Vatury O, Slotkin TA. Cell signaling as a target and underlying mechanism for neurobehavioral teratogenesis. Ann NY Acad Sci.2002; 965:473-478.

Zurich MG, Honegger P, Schilter B, Costa LG, Monnet-Tschudi F. Use of aggregating brain cell cultures to study developmental effects of organophosphorus insecticides. Neurotoxicology.2002; 21:599-605. 


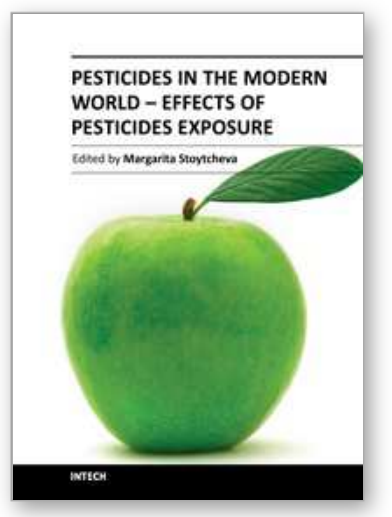

\author{
Pesticides in the Modern World - Effects of Pesticides Exposure \\ Edited by Dr. Margarita Stoytcheva
}

ISBN 978-953-307-454-2

Hard cover, 376 pages

Publisher InTech

Published online 12, September, 2011

Published in print edition September, 2011

The introduction of the synthetic organochlorine, organophosphate, carbamate and pyrethroid pesticides by 1950â $€^{\mathrm{TM}} \mathrm{s}$ marked the beginning of the modern pesticides era and a new stage in the agriculture development. Evolved from the chemicals designed originally as warfare agents, the synthetic pesticides demonstrated a high effectiveness in preventing, destroying or controlling any pest. Therefore, their application in the agriculture practices made it possible enhancing crops and livestockâ $\epsilon^{\mathrm{TM}} \mathrm{s}$ yields and obtaining higher-quality products, to satisfy the food demand of the continuously rising worldâ $€^{\mathrm{TM}_{\mathrm{M}}}$ population. Nevertheless, the increase of the pesticide use estimated to 2.5 million tons annually worldwide since 1950 ., created a number of public and environment concerns. This book, organized in two sections, addresses the various aspects of the pesticides exposure and the related health effects. It offers a large amount of practical information to the professionals interested in pesticides issues.

\title{
How to reference
}

In order to correctly reference this scholarly work, feel free to copy and paste the following:

Binukumar B.K and Kiran Dip Gill (2011). Chronic Exposure to Pesticides- Neurological, Neurobehavioral and Molecular Targets of Neurotoxicity, Pesticides in the Modern World - Effects of Pesticides Exposure, Dr. Margarita Stoytcheva (Ed.), ISBN: 978-953-307-454-2, InTech, Available from:

http://www.intechopen.com/books/pesticides-in-the-modern-world-effects-of-pesticides-exposure/chronicexposure-to-pesticides-neurological-neurobehavioral-and-molecular-targets-of-neurotoxicity

\section{INTECH}

open science | open minds

\section{InTech Europe}

University Campus STeP Ri

Slavka Krautzeka 83/A

51000 Rijeka, Croatia

Phone: +385 (51) 770447

Fax: +385 (51) 686166

www.intechopen.com

\section{InTech China}

Unit 405, Office Block, Hotel Equatorial Shanghai

No.65, Yan An Road (West), Shanghai, 200040, China

中国上海市延安西路65号上海国际贵都大饭店办公楼 405 单元

Phone: +86-21-62489820

Fax: $+86-21-62489821$ 
(C) 2011 The Author(s). Licensee IntechOpen. This chapter is distributed under the terms of the Creative Commons Attribution-NonCommercialShareAlike-3.0 License, which permits use, distribution and reproduction for non-commercial purposes, provided the original is properly cited and derivative works building on this content are distributed under the same license. 